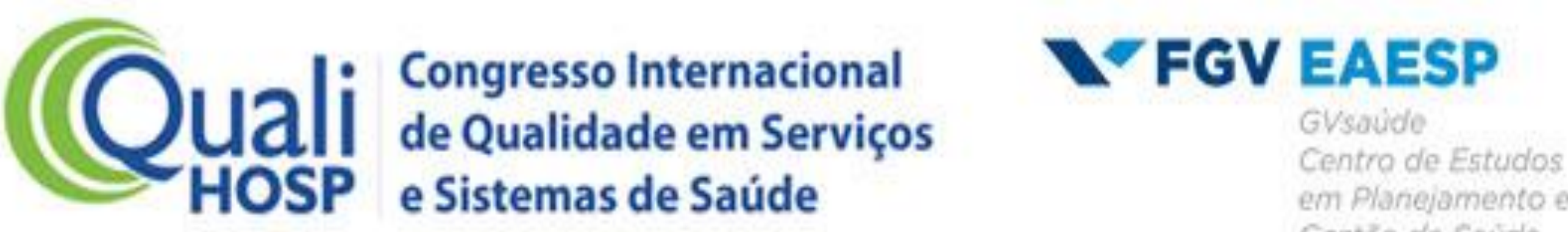

Gilmara Furtado Reis Penteado, Patrícia do Prado Costa Braga, Roseli Gomes Cavalini, Tatiane Cristina Abreu Vale

\section{EFETIVIDADE NA PUNÇÃO VENOSA PARA INSERÇÃO DE CATETER CENTRAL DE INSERÇÃO PERIFÉRICA NO BLOCO PEDIÁTRICO DE UM HOSPITAL PÚBLICO DO ALTO TIETÊ}

Eixo temático: Avaliação e Qualidade do Cuidado

INTRODUÇÃO: O uso do Cateter Central de Inserção Periférica (CCIP) encontra-se em expansão devido aos resultados positivos de seu emprego, um maior conhecimento dos enfermeiros acerca dos diversos dispositivos vasculares e suas indicações, o desenvolvimento de materiais mais biocompatíveis na fabricação de CCIP e o melhor gerenciamento dos riscos com maior segurança e conforto para o paciente são fatores determinantes ademais a inserção do CCIP, além de trazer benefícios assistenciais e econômicos para a instituição, significa também humanizar a assistência prestada, poupando os pacientes a exposição da dor devido as múltiplas punções periféricas. .

OBJETIVO: Identificar a efetividade na punção venosa para inserção de CCIP no bloco pediátrico, em um Hospital Público no município de Mogi das Cruzes.

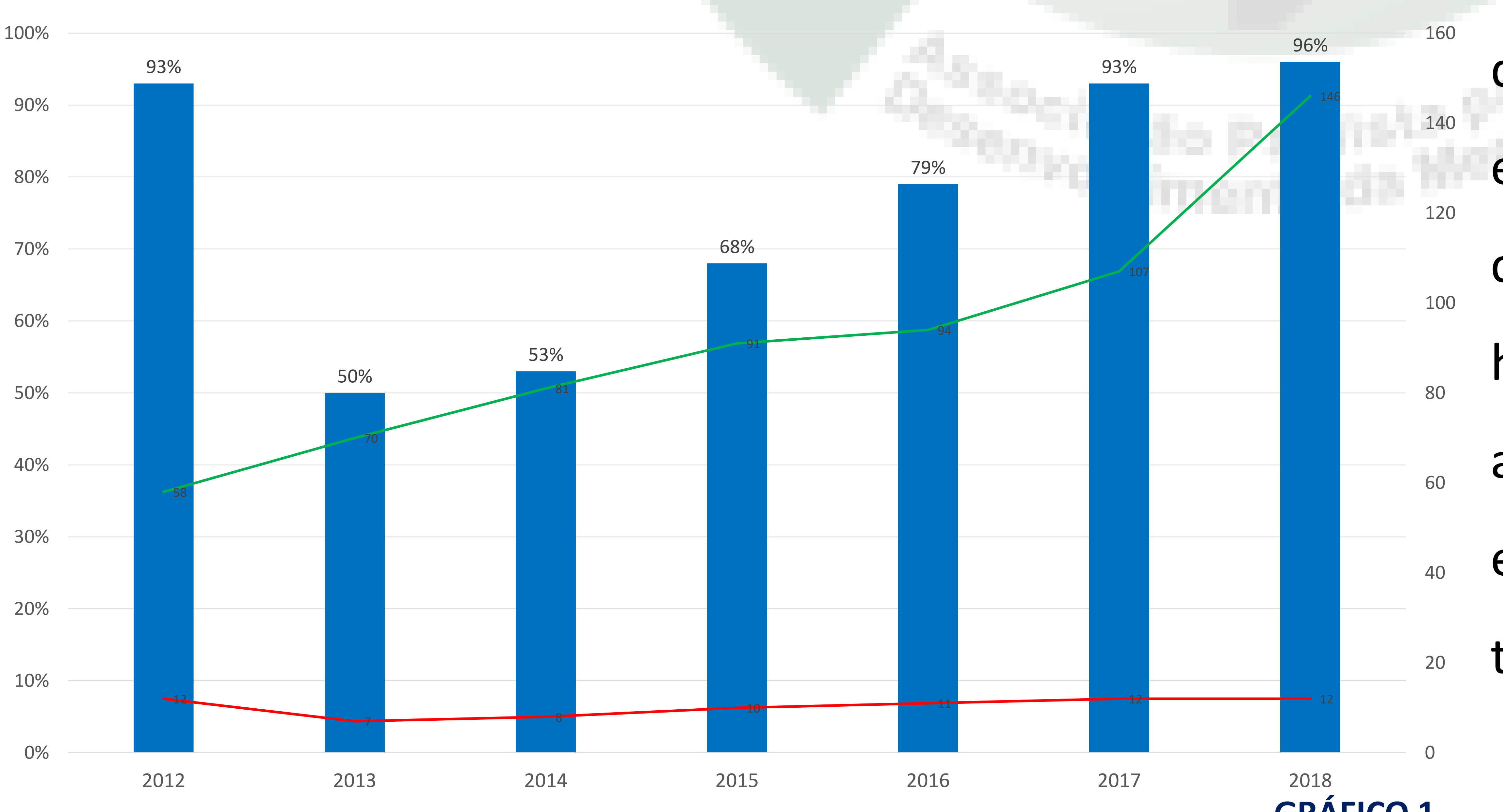

MÉTODO: Trata-se de uma pesquisa de abordagem quantitativa do tipo análise retrospectiva. Para a obtenção das informações necessárias para a realização do presente estudo, foram utilizados indicadores do ano de setembro 2011 a setembro 2018.

RESULTADOS: Verificamos que foram inseridos 585 cateteres em crianças de diferentes perfis, desde setembro de 2011 à setembro de 2018 com uma efetividade de passagem de $90 \%$, uma média de permanência de 11 dias (variando de 0 à 56 dias de uso) conforme observamos no gráfico 1 , tendo como motivo principal de sua retirada o término do tratamento.

CONCLUSÃO: Verificamos que ao longo dos sete anos, a utilização do cateter e a efetividade da punção vem sendo uma crescente, a equipe de enfermeiros habilitados na passagem de CCIP apresentam um bom aproveitamento na escolha dos pacientes e na aplicação das técnicas para inserção do cateter .

GRÁFICO 1

REFERÊNCIAS: 1- Negeliskii C. e col. Custo benefício do cateter central de inserção periférica em comparação com o cateter venoso central. Revista Eletrônica Estácio Saúde - Volume 6, Número 1, 2017

2-Baiocco G. G. A utilização do cateter central de inserção periférica no ambiente hospitalar Tese de Mestrado pelo Programa de Pós-Graduação em Medicina e Ciências da Saúde da PUC do Rio Grande do Sul 2009. 